\title{
Applying an e-PBL Platform to Develop a Storytelling-Based Arithmetic Card Game
}

\author{
Li Ling $\mathrm{Hu}^{1, \mathrm{a}}$ and Shian Shyong Tseng ${ }^{2}$ \\ ${ }^{1}$ Department of Computer Science and Information Engineering, Asia University, Taiwan (R.O.C.); Department of Digital Media Design, \\ Tatung Institute of Technology, Taiwan (R.O.C.) \\ ${ }^{2}$ Department of M-Commerce and Multimedia Applications, Asia University, Taiwan (R.O.C.)
}

\begin{abstract}
Mathematics is a very important learning subject. Mathematical knowledge can be learned by traditional or distance learning, but the mathematical problem solving ability is hard to improve without experiences through practice. Therefore, developing an interesting learning game to enhance students' problem solving ability is the major concern in this paper. Since the storytelling strategy has been proved to be useful to enhance the students thinking ability, we develop a storytelling-based arithmetic card game to encourage and guide students to speak out their thinking process of problem solving, where the e-Project-Based Learning (e-PBL) platform has been applied to brainstorm the characteristics of the game and construct the storytelling script. Thus, the misconceptions can be easily diagnosed. To evaluate the performance of our approach, 40 5-grade primary school students have participated in the storytelling-based arithmetic card game experiment. The experimental result shows that the storytelling-based learning can enhance the mathematical problem solving ability via playing the game.
\end{abstract}

\section{Introduction}

Mathematics is a very important learning subject which can be directly or indirectly applied to solve a lot of real problems in our daily life. In addition to mathematical concepts or knowledge, problem solving ability including inference ability, abstract ability, and calculating ability is also very important [1]. Mathematical concepts or knowledge can be learned by traditional or distance learning, but the problem solving ability is hard to improve without experiences through practice. As we know, game-based learning is a promising approach to enhance the students learning interest and motivation. Therefore, developing an interesting learning game to enhance students' problem solving ability is the major concern in this paper.

There are a lot of mathematical games to assist and enhance students' mathematical knowledge or ability, such as 2048, Decimal Number Puzzles, Sum Tracks, and so on. But, the traditional arithmetic games rarely diagnose players' misconception in mathematics. Since the storytelling strategy has been proved to be useful to enhance the students thinking ability, it will be adopted to encourage and guide students to speak out their thinking process of problem solving. Thus, the misconceptions can be easily diagnosed.

The e-Project-Based Learning (e-PBL) platform can be applied to brainstorm the characteristics of the game and construct the storytelling script in game developing [3-4]. Therefore, our idea is to use it to develop an arithmetic card game to enhance students' mathematical problem

a Corresponding author: jasmine819@gmail.com solving ability. But, applicable techniques are still needed to construct the storytelling script, including scenes and interactive dialogues, to guide students speak out and improve the learning effectiveness [5-6]. For finding the way of student's thinking, we need to find the strategy used by students in problem solving. As we know, problem decomposition strategy, the basic one for reducing the problem difficulty, could be recursively applied to decompose the original problem into several simple sub-problems, and therefore the backward reasoning can be embedded in the storytelling script construction as the scaffolding for learning. The 24 Game, an arithmetical card game, consists of four cards and combines them to 24 with addition, subtraction, multiplication, or division operations [2]. Since it can be easily decomposed into sub-problems, it will be used as an example to illustrate our idea. Firstly, we define $X$ card $Y$ game to represent the arithmetical card game consisting of $\mathrm{X}$ cards and combining them to $\mathrm{Y}$ with addition, subtraction, multiplication, or division operations. And then, the 4-card 24 game can be decomposed to a 3-card game or a 2-card game according to whether some card being used as an operand of the chosen last arithmetic operation. Similarly, the 3-card game can be further decomposed to a 2-card game. Accordingly, the students can enhance the inference ability, abstract ability, calculating ability, and recursive concept via the arithmetic card game.

The backward reasoning ability of students can be trained to infer the solution of the 4-card 24 game and 
their misconceptions in mathematical problem solving ability can then be diagnosed. In this paper, we focus on developing a storytelling-based arithmetic card game.

Based on the e-PBL platform, the arithmetic card game development consists of game analysis phase, storytelling construction phase, and game developing phase, where each phase consists of four steps, case inquiry, brainstorming, collaborating and discussing, to provide appropriate case scaffolding. The students brainstorm and achieve the storytelling-based game collaboratively in each phase. The students' learning path will be stored as their learning portfolio.

To evaluate the effectiveness of our approach, 40 5grade primary school students have played the arithmetic card game to enhance the mathematical problem solving ability, and 34 students got the good learning performance in the assessment. It means that the storytelling-based learning can enhance the mathematical problem solving ability via playing the game.

\section{Related works}

\subsection{Learning by storytelling}

Since 2010, storytelling has been widely used in learning knowledge and skills. Storytelling allows students to collect information, to stimulate ideas, and to encourage students organize their knowledge structure from the storyline [7]. It is a good approach for improving students' learning motivation and establishing self-confidence [814]. Hung et al. [15] claimed that the storytelling can improve students' learning motivation, problem-solving ability, and learning achievement.

As mentioned above, many tools have been proposed in enhancing students' learning. However, it is required to construct storytelling script for learning by storytelling. Moreover, problem decomposing strategy will be applied in this paper to help students inferring the solution of the 24 Game and then enhancing students' mathematical problem solving ability. Thus, how to construct storytelling scenes and interactive dialogues for students learning becomes an important and interesting issue.

\section{2 e-PBL}

PBL has been proved to be an effective learning strategy [16]. With the progress of new era, e-PBL (PBL joins the IT technology) is used as a powerful tool to simulate the dangerous or expensive projects and provide scaffolding assist students learning [17-18]. However, without good platform, the previous cases cannot be properly stored and reused, and the achievement cannot be easily assessed. PBL platform using CBR (Case Base Reasoning) techniques is a good e-PBL platform to provide the case scaffoldings and reserve the learning portfolio [19]. The e-PBL platform is a multi-spiral learning model. In the spiral learning model, the learning objectives can be gradually achieved from outside to inside, each of which can be beneficial from the e-PBL platform using CBR techniques.
Therefore, e-PBL using CBR techniques can provide appropriate learning scaffolding to assist students and improve learning performance.

\section{Applying e-PBL to Develop a Storytelling-Based Arithmetic Card Game}

\section{1 e-PBL Platform for Arithmetic Card Game}

The e-PBL platform in $\mathrm{Hu}$ et al. [19] has been modified for developing arithmetic card game using problem decomposition strategy, as shown in Figure 1. It consists of game analysis phase, storytelling construction phase, and game developing phase. The e-PBL platform is a multi-step spiral model, each spiral of e-PBL platform corresponds to a phase, each phase consisting of four steps: case inquiry, brainstorming, collaborating and discussing.

Step1. Case inquiry: CBR case retrieve technique is used to inquire appropriate case scaffoldings.

Step2. Brainstorming: CBR case reuse or case revise technique is used to assist student to brainstorm.

Step3. Collaborating: Students collaborate to stimulate the brainstorming outcome.

Step4. Discussing: CBR case retain technique is used to assist student to discuss experiences.

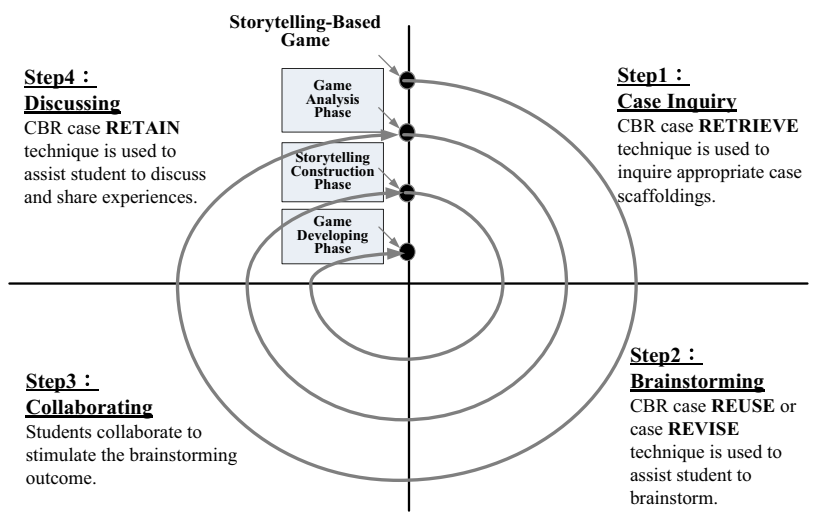

Figure 1.The multi-step spiral e-PBL platform for developing arithmetic card game.

\subsection{Phases on e-PBL Platform}

For illustrate our idea, the formal definition of the game is given as below.

Definition: $\mathbf{X}$-card $\mathbf{Y}$ game is an arithmetic card game consists of $\mathrm{X}$ cards and combines them to $\mathrm{Y}$ with addition, subtraction, multiplication, or division operations, where $\mathrm{X}=2,3,4$ and $\mathrm{Y}=1,2, \ldots, 24$.

We use the 4-card 24 game as an example to elaborate the application of e-PBL platform to develop a storytelling-based arithmetic card game for assisting students to enhance mathematical problem solving ability, including inference ability, abstract ability, and calculating ability. The development of the storytellingbased arithmetic card game can be divided into game analysis phase, storytelling construction phase, and game developing phase. 


\subsubsection{Game Analysis Phase}

In case inquiry step, the CBR case retrieve technique is used to inquire appropriate case as the case scaffoldings. In brainstorming step, the CBR case reuse or case revise technique is used to assist student to analyse the characteristics of 4-card 24 game. As shown in Figure 2, the AND/OR tree, which is a tree structure of the reduction of problems to conjunctions and disjunctions of sub-problems, can be used to represent the decomposition process of the 4-card 24 game. It can be seen that the 4card 24 game can be decomposed to three cases according to whether some card being used as an operand of the chosen last arithmetic operation:

(1). If some card is used as the first operand, the 4-card 24 game is decomposed to 3 -card game.

(2). If some card is used as the second operand, the 4card 24 game is decomposed to 3 -card game.

(3). Otherwise, the 4-card 24 game is decomposed to two 2 -card games.

The 3-card game can be further decomposed to a 2card game. Therefore, the students can learn the recursive concept in the arithmetic card game. In collaborating step, students collaborate to stimulate the brainstorming outcome. In discussing step, the students discuss and clarify the learning process of the phase and share their experiences with each other.

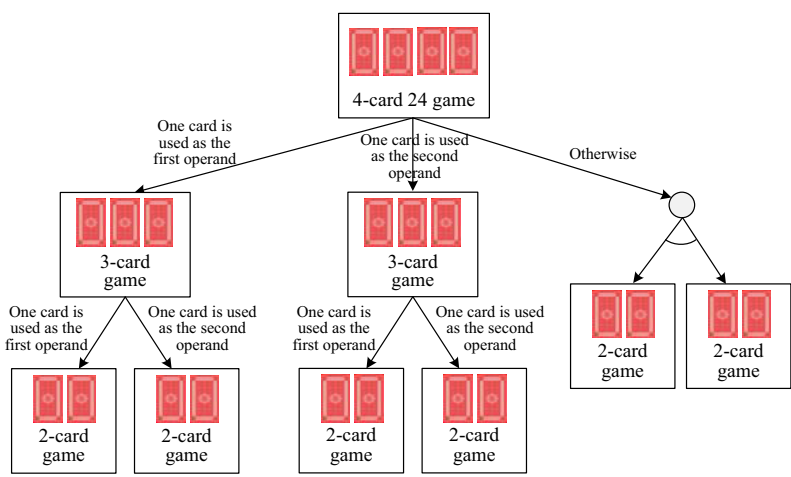

Figure 2. The characteristics of 4-card 24 game.

\subsubsection{Storytelling Construction Phase}

In case inquiry step, the CBR case retrieve technique is used to inquire appropriate case as the case scaffoldings. In brainstorming step, the CBR case reuse or case revise technique is used to assist student to brainstorm the storytelling script and assessment framework; the storytelling script consists of scenes and interactive dialogues; the assessment framework consists of the concept index and ability index. As mentioned in analysis phase, the storytelling script can be composed of the dialogues and the scenes of solving 4-card game, 3-card game, and 2-card game, as shown in Figure 3, Figure 4, and Figure 5, respectively, where the backward reasoning method is used to guide students to infer the solution in each scene. According to mathematics education target [1], the mathematical problem solving ability consists of inference ability, abstract ability, and calculating ability. The relationship between the scenes of the game and the problem solving abilities is shown in Table 1 for helping the diagnosis of the students' misconception in mathematics. In each scene, students brainstorm with the interactive dialogues, as shown in Table 2. Some game rules which can assist students to infer whether the final operation could be a multiplication are shown in Table 3 . The collaborating and discussing steps are the same as those in the previous phase.

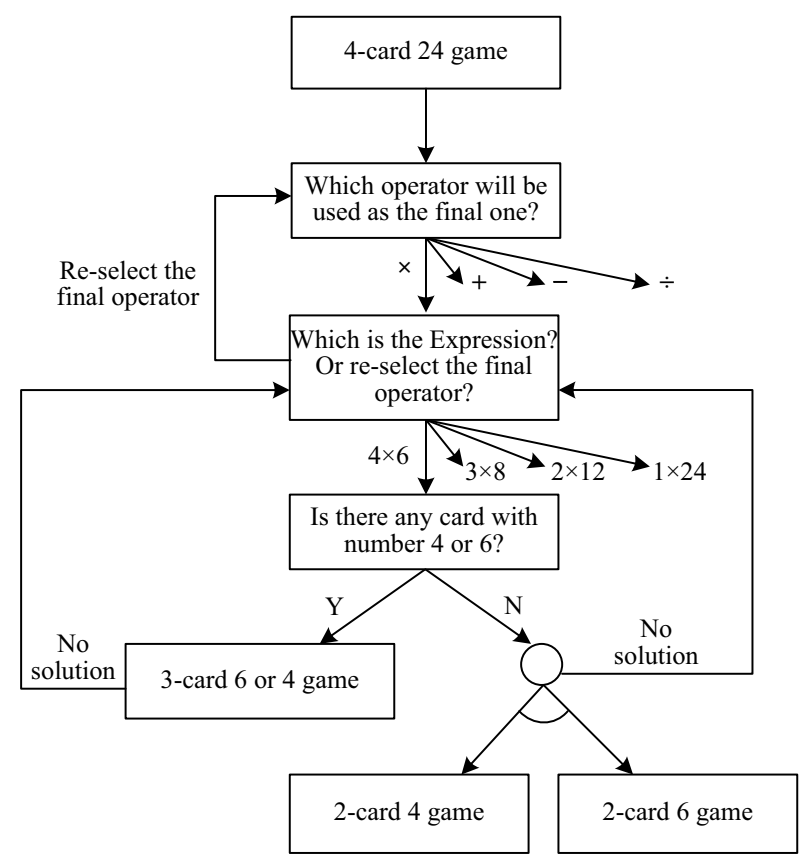

Figure 3. The dialogues and the scenes of solving 4-card game.

(a). The final operator is "”" or "-."

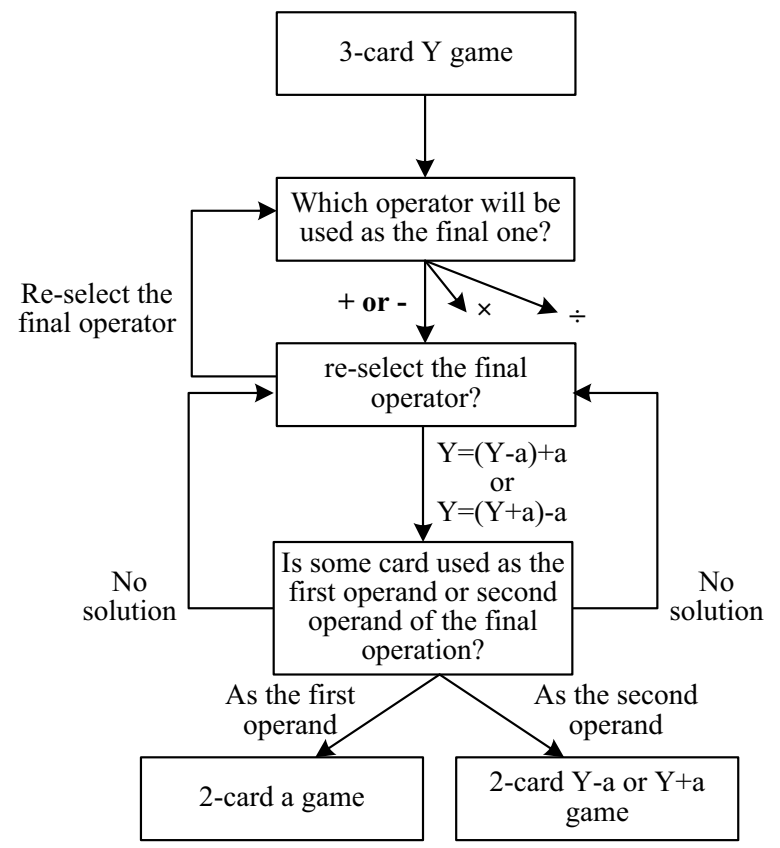


(b). The final operator is " $x$ "

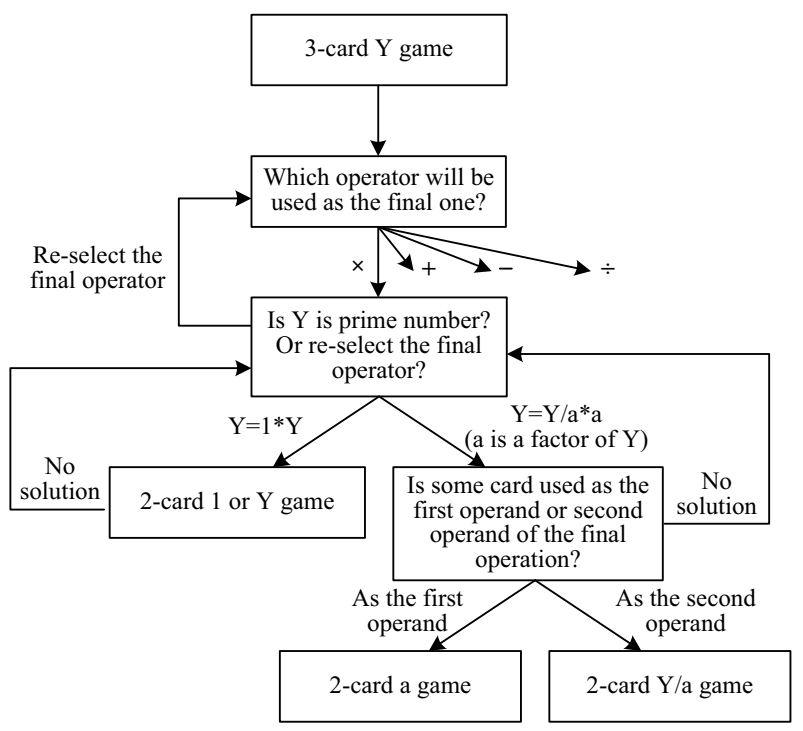

(c). The final operator is ":

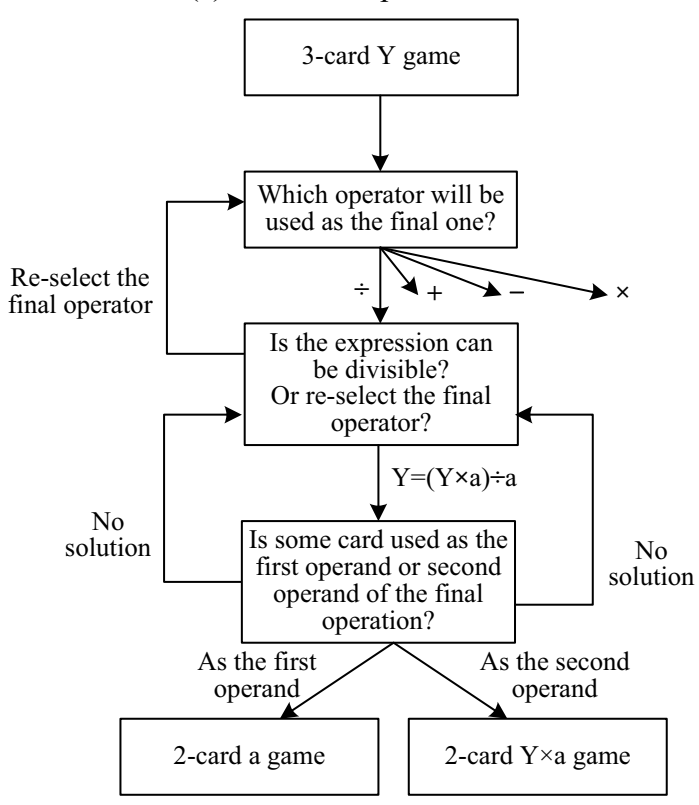

Figure 4. The dialogues and the scenes of solving 3-card game.

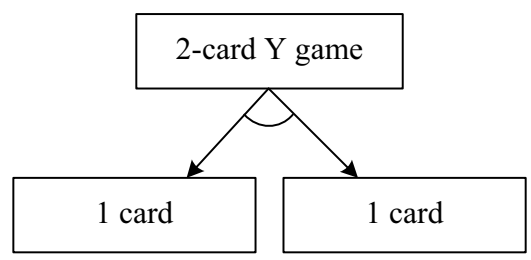

Figure 5. The scenes of solving 2-card game.

Table 1. The relationship between the scenes and abilities.

\begin{tabular}{|c|c|}
\hline Scene & Pbility \\
\hline 4-card scene & Inference ability \\
\hline 3-card scene & Abstract ability \\
\hline 2-card scene & Calculating ability \\
\hline
\end{tabular}

Table 2. The storytelling interactive dialogues.

\begin{tabular}{|c|l|}
\hline Scene Dialogues & \multicolumn{1}{|c|}{ Storytelling interactive dialogues } \\
\hline 4-card game & $\begin{array}{l}\text { 1. Which operator will be used as the } \\
\text { final one? } \\
\text { 2. Which is the expression? } \\
\text { Or re-select the final operator? } \\
\text { 3. Is there any card with number ( ) }\end{array}$ \\
\hline \multirow{5}{*}{$\begin{array}{l}\text { 1. Which operator will be used as the } \\
\text { final one? } \\
\text { 2.Is ( ) a prime number? } \\
\text { Or re-select the final operator? } \\
\text { 3.Is the expression can be divisible? } \\
\text { Or re-select the final operator? } \\
\text { 4.Is some card used as the first operand } \\
\text { or second operand of the final } \\
\text { operation? }\end{array}$} \\
\hline
\end{tabular}

Table 3. The game rules.

\begin{tabular}{|l|}
\hline \multicolumn{1}{|c|}{ Game rules } \\
\hline $\begin{array}{l}\text { If there exist two cards with two consecutive numbers, } \\
\text { then these cards can be combined to } 1 \text {. }\end{array}$ \\
\hline $\begin{array}{l}\text { If there exist two cards with the same number, then these } \\
\text { cards can be combined to } 0 \text { or } 1 \text {. }\end{array}$ \\
\hline $\begin{array}{l}\text { If there exist three cards with three consecutive numbers, } \\
\text { then these cards can be combined to any one of three } \\
\text { numbers. }\end{array}$ \\
\hline $\begin{array}{l}\text { If there exist three cards with the same number, then } \\
\text { these cards can be combined to the number. }\end{array}$ \\
\hline
\end{tabular}

\subsubsection{Game Developing Phase}

In case inquiry step, the CBR case retrieve technique is used to inquire the similar case as case scaffoldings. In brainstorming step, the CBR case reuse or case revise technique is used to assist student to brainstorm the context of the game. In collaborating step, students develop the storytelling-based arithmetic card game collaboratively. In discussing steps is the same as those in the previous phase.

\section{Experiment}

With the storytelling-based arithmetic card game, students can accumulate the experiences through practice and enhance their mathematical problem solving ability during playing the game. When the game started, if the students did not solve the problem by themselves, the interactive dialogues will be provided to assist and guide them to solve the problem.

405 -grade primary school students can enhance the mathematical problem solving ability through the arithmetic card game. Before the game playing, we firstly introduce the 24-card game to the students, and showed them related website arithmetic learning games. As shown in Figure 6, 34 students have the high learning performance. It means that the storytelling-based learning system can enhance students' mathematical problem solving ability. 


\section{The Learning Performance}

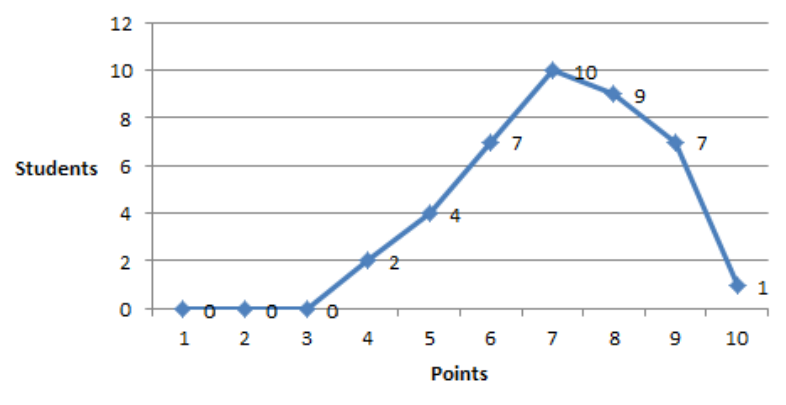

Figure 6. The learning performance of 405 -grade students.

\section{Conclusions}

For accumulating students' experiences through practice, we apply an e-PBL platform to develop a storytellingbased arithmetic card game to assist students to enhance mathematical problem solving ability. Applying the ePBL platform, students brainstorm the characteristics of the game and the storytelling interactive dialogues. The experimental result shows the backward reasoning method combining the recursive problem decomposition strategy can guide students to infer the solution of 4-card 24 game. In the near future, we will focus on finding players' frequent error pattern from their learning portfolio in order to analyse the students' misconception.

\section{Acknowledgements}

This work was partially supported by the National Science Council of the Republic of China under grants MOST 104-2511-S-468-002-MY2 and MOST 104-2511S-468-005-MY2.

\section{References}

1. Information on http://teach.eje.edu.tw/data/files/class rules/math.pdf, (2015)

2. Information on https://en.wikipedia.org/wiki/24 Game, (2015)

3. P.H. Hung, G.J. Hwang, Y.H. Lee, T.H. Wu, B. Vogel, M. Milrad, E. Johansson, A Problem-based Ubiquitous Learning Approach to Improving the Questioning Abilities of Elementary School Students, Educational Technology \& Society, 17(4) (2014) 316-334

4. H.S. Barrows, Problem-based learning in medicine and beyond: A brief overview, New Directions for Teaching and Learning, 68 (1996) 3-12

5. G.J. Hwang, Y.R. Shih, H.C. Chu, A concept map approach to developing collaborative Mind-tools for context-aware ubiquitous learning. British Journal of Educational Technology, 42(5) (2011) 778-789

6. C.E. Mora Luis, J.M. Gutierrez, A.M. González Marrero, Using mobile devices and internet technologies in problem-based learning: Design of a suitable active and collaborative learning environment in engineering education, Frontiers in Education Conference (FIE), 2014

7. L. Malita, C. Martin, Digital Storytelling as web passport to success in the 21st Century, ProcediaSocial and Behavioral Sciences, 2(2) (2010) 30603064

8. T. Grisham, Metaphor, poetry, storytelling and crosscultural leadership, Management Decision, 44(4) (2006) 486-503

9. C. Haigh, P. Hardy, Tell me a story - a conceptual exploration of storytelling in healthcare education, Nurse Education Today, doi: 10.1016/j.nedt.2010.08.001, (2010)

10. P.R. Lowenthal, Digital storytelling: An emerging institutional technology? In K. McWilliam \& J. Hartley (Eds.), Story circle: Digital storytelling around the world, Oxford: Wiley-Blackwell, (2009) 252-259

11. P.R. Lowenthal, J.C. Dunlap, From pixel on a screen to real person in your students' lives: Establishing social presence using digital storytelling, The Internet and Higher Education, 13(1-2) (2010) 70-72

12. G. Stacey, P. Hardy, Challenging the shock of reality through digital storytelling, Nurse Education in Practice, 11(2) (2011) 159-164

13. K. Gyabak, H. Godina, Digital storytelling in Bhutan: A qualitative examination of new media tools used to bridge the digital divide in a rural community school, Computers \& Education, 57(4) (2011) 2236-2243

14. Y. T. C. Yang, W. C. I. Wu, Digital storytelling for enhancing student academic achievement, critical thinking, and learning motivation: A year-long experimental study, Computers \& Education, 59(2) (2012) 339-352

15. C. M. Hung, G. J. Hwang, I. Huang, A Project-based Digital Storytelling Approach for Improving Students' Learning Motivation, Problem-Solving Competence and Learning Achievement, Educational Technology \& Society, 15(4) (2012) 368-379

16. P.C. Blumenfeld, E. Soloway, R.W. Marx, J.S. Krajcik, M. Guzdial, A. Palincsar, (1991). Motivating Project-Based Learning: Sustaining the Doing, Supporting the Learning, Educational Psychologist, 26(3-4) (1991) 369-398

17. B. Rienties, B. Giesbers, D. Tempelaar, S. LygoBaker, M. Segers, W. Gijselaers, The role of scaffolding and motivation in CSCL, Computers \& Education, 59(3) (2012) 893-906.

18. H.C. Chu, G.J. Hwang, Development of a projectbased cooperative learning environment for computer programming courses, International Journal of Innovation and Learning, 8(3) (2010) 256-266.

19. L.L. Hu, S.S. Tseng, J.F. Weng, Building ProjectBased Learning Platform for the Capstone Project, 23rd International Conference on Computers in Education, Nov 2015. 